BMJ Nutrition, Prevention \& Health

\title{
Association between vitamin intake and respiratory complaints in adults from the UK National Diet and Nutrition Survey years 1-8
}

Suzana Almoosawi, ${ }^{1,2}$ Luigi Palla ${ }^{2,3,4}$

To cite: Almoosawi S,

Palla L. Association between vitamin intake and respiratory complaints in adults from the UK National Diet and Nutrition Survey years 1-8. BMJ Nutrition, Prevention \& Health 2020;3:e000150. doi:10.1136/ bmjnph-2020-000150

${ }^{1}$ School of Public Health, Imperial College London, London, UK

${ }^{2}$ NNEdPro Global Centre for Nutrition and Health, Cambridge, United Kingdom

${ }^{3}$ Faculty of Epidemiology and Population Health, London

School of Hygiene \& Tropical Medicine, London, UK ${ }^{4}$ Department of Global Health, School of Tropical Medicine and Global Health, Nagasaki University, Nagasaki, Japan

Correspondence to Dr Suzana Almoosawi, Imperial College London, London W6 8RP, UK;

s.almoosawi@imperial.ac.uk

Received 4 August 2020 Revised 2 September 2020 Accepted 7 September 2020 Published Online First 27 October 2020

Check for updates

(C) Author(s) (or their employer(s)) 2020. Re-use permitted under CC BY-NC. No commercial re-use. See rights and permissions. Published by BMJ.

\section{ABSTRACT}

Objective To examine the cross-sectional association between vitamins A, E, C and D from diet and supplements and the prevalence of respiratory complaints in a nationally representative sample of UK adults.

Methods Data from adult participants of the National Diet and Nutrition Survey Rolling Programme years 2008-2016 were used for the analysis. Logistic regression adapted for complex survey design was used to investigate the relationship between each vitamin intake in turn (exposure) and self-reported respiratory complaints (outcome), adjusting for relevant confounders.

Results Overall, respiratory complaints were found in 33 of the 6115 adult patients aged 19 years and above. After adjustment for potential confounders, a negative association was observed between the intake of vitamin $A$ and $E$ intake from diet and supplements and respiratory complaints. For vitamin D, intake from supplements, but not diet, was inversely significantly associated with respiratory complaints. No association between vitamin C and respiratory complaints was observed.

Conclusion In conclusion, intake of vitamin $A$ and $E$ from diet and supplements, and vitamin D from supplements, show strong evidence of association with lower selfreported prevalence of respiratory complaints in a nationally representative sample of UK adults.

\section{BACKGROUND}

Globally, there has been an emerging trend of pandemics affecting the respiratory system, which has culminated most recently in the severe acute respiratory syndrome coronavirus 2019 outbreak. ${ }^{1}$ Current efforts to tackle the pandemic rely on managing associated symptoms and providing standard supportive nutritional care, with a substantial burden on the National Health Service. ${ }^{2}$

Nutrition is known to play a critical role in the prevention of a number of infectious diseases, while malnutrition is known to contribute to increased morbidity and mortality from such diseases. ${ }^{34}$ Although the mechanisms by which nutrition affects immunity are complex, optimal nutritional status is known to contribute to the maintenance of the immune system. ${ }^{56}$ Evidence also suggests that unhealthy western diets contribute to chronic inflammation and reduced host defence against viruses. ${ }^{7}$ Consistent with the latter, the beneficial role of specific nutrients, such as vitamins $\mathrm{A}, \mathrm{E}, \mathrm{C}$ and $\mathrm{D}$, in the prevention of acute respiratory complaints is emerging and has been highlighted recently by a number of reviews and a report by the American Nutrition Association. ${ }^{6}$ 8-11 According to the latter report, vitamin A is speculated to support mucosal tissues, and practitioners were advised to evaluate doses that exceed the recommended dietary allowance of $700 \mu \mathrm{g} / 2333 \mathrm{IU}$ retinoic acid equivalent for women and $900 \mu \mathrm{g} / 3000 \mathrm{IU}$ retinoic acid equivalent for men, respectively. ${ }^{10}$ Likewise, vitamin $\mathrm{E}$ has been hypothesised to play a role in lung protection through its fat-soluble properties, which enable it to accumulate in lipid membranes, neutralising free-radicals and triggering production of proinflammatory cytokines. ${ }^{10}$ Evidence for vitamin $\mathrm{C}$ in supporting white blood cells to fight infections is more established, ${ }^{6}$ while a number of reviews and studies indicate the potential health benefits of taking vitamin D supplements, particularly in individuals who are deficient. ${ }^{611}$ More recently, a number of studies have highlighted the consequences of malnutrition and the role of vitamin supplementation in managing the severity and longterm consequences of coronavirus disease. ${ }^{712}$

On the balance of this evidence, there is clearly an urgent need to expand our understanding of how intake of vitamins from dietary sources and supplements could influence the incidence and severity of respiratory complaints. This understanding is critical to developing short-term and long-term public health nutrition recommendations to help tackle respiratory complaints and reduce burden on healthcare systems. 
This study aimed to examine the cross-sectional association between vitamins $\mathrm{A}, \mathrm{E}, \mathrm{C}$ and $\mathrm{D}$ intake from diet and supplements and the prevalence of respiratory complaints in a nationally representative sample of UK adults. These vitamins were selected among many nutrients as they have already been granted health claims in the European Union relating to the normal function of the immune system ${ }^{13}$ and have been hypothesised by the American Nutrition Association to be of value to the prevention of respiratory infections. ${ }^{10}$

\section{METHODS}

The study population consisted of adults aged 19 years and above who participated in the 2008-2016 National Diet and Nutrition Survey Rolling Programme (NDNS RP) and who completed three or more days of diet diaries. The NDNS RP is a cross-sectional rolling survey that collects information yearly on all food and drinks consumed from approximately 1000 randomly sampled individuals living in private households across the four regions in the UK. ${ }^{14}$

Individuals were selected from a random sample of 21573 addresses from 799 postcode sectors obtained between April 2008 and March 2011 from the Royal Mail's postcode address file in years $1-4$. In years 5 and 6 (combined), a random sample of 8879 addresses from 323 postcode sectors was drawn between April 2012 and March 2014. ${ }^{15}$ In years 7 and 8 (combined), the sample was expanded to 9072 addresses from 316 postcode sectors. Within each selected address, one household was randomly sampled. The overall response rate for individuals completing 3 or 4 days of dietary records was $56 \%$ in year $1,57 \%$ in year $2,53 \%$ in year $3,55 \%$ in year $4,53 \%$ in the combined years 5 and 6 and $53 \%$ in the combined years 7 and 8 , respectively. Details of the survey methodology have been published previously. ${ }^{14}$ Ethical approval for the NDNS $\mathrm{RP}$ was obtained from Oxfordshire A Research

Ethics committee approval (Ref. No. 07/H0604/113) and for NDNS RP 2014-2017 approval from the Cambridge South NRES Committee (Ref. No. 13/ $\mathrm{EE} / 0016)$ was received.$^{14}$

Respiratory complaints were defined as the selfreported presence of a number of conditions, such as weak chest, breathlessness, bronchial trouble, collapsed lung, lung damage by viral pneumonia, throat infection and others. Full description is provided in the interviewer project instructions of the NDNS programme. ${ }^{16}$

Design-based inference by logistic regression adapted for complex surveys (with software Stata 16) to accommodate the survey design (clusters, strata and weights) was applied to explain the presence of respiratory condition for each vitamin in a separate model, comprising both intake from diet only (continuous exposure) and from supplements (binary exposure) and adjusting for relevant confounders-that is, age, sex, body mass index (BMI), smoking (current, former or never), equivalised income and total energy intake. Data were weighted to correct
Box 1 Summary of current evidence and main findings

What is already known on this topic

- Good nutrition and vitamin supplementation may help prevent respiratory infections.

- Evidence from nationally representative observational studies is limited.

\section{What this study adds}

- Intake of vitamins A and E from both diet and supplements is associated inversely with prevalence of respiratory complaints in UK adults.

- Vitamin D intake from supplements, but not diet, is associated inversely with prevalence of respiratory complaints in UK adults.

Next steps

- Conduct longitudinal studies on vitamin intake and respiratory infections to disentangle the direction of causality.

- Conduct studies on the relationship between vitamin intake and immunity to COVID-19, including diverse ethnic groups.

for unequal sample selection, non-response for household and individual interview, and non-response to individual visit. The weighing factor adjusted for differences in sociodemographic variables, such as age, sex, ethnicity and region, between participants and non-participants to the individual and nurse visit, ensuring the survey sample was representative of the UK population. Analyses were conducted using the centred method for singleton strata.

Intake from supplements was calculated by subtracting total intake for each vitamin from its corresponding dietary intake. Intake was subsequently categorised as 'yes/no' to account for excess zeroes and non-normal distribution of intake from supplements.

\section{RESULTS AND DISCUSSION}

The overall findings are summarised in box 1. Sample characteristics are shown in table 1. Overall, in the unweighted sample, there were 33 cases of respiratory complaints out of the 6115 adult cases. Survey members who reported respiratory complaints were generally older $(\mathrm{p}=0.025)$ and less likely to report taking vitamins A, E, C or $\mathrm{D}$ supplements. Intake of vitamin $\mathrm{E}$ and $\mathrm{A}$ from diet was also lower in survey members who reported respiratory complaints than in those who did not report such complaints.

In the crude analysis, intake of vitamin $\mathrm{D}, \mathrm{E}$ and $\mathrm{A}$ supplements was associated with a lower prevalence of respiratory complaints (table 2 ).

This association remained after adjustment for age and sex, BMI, household income and smoking status. For continuous exposure, only vitamin $\mathrm{A}$ and $\mathrm{E}$ intake from diet remained significantly associated with lower respiratory complaints and the direction and magnitude of the association remained the same and similar. In the case of vitamin $\mathrm{D}$, the association between intake from diet and respiratory complaints switched from positive to negative between the crude and fully-adjusted model while 
Table 1 Characteristics of the unweighed population sample. Continuous data are shown as mean and SD. Categorical data are shown as counts and percentages. The null hypothesis that the mean is the same in those reporting/not reporting respiratory complaints is tested taking full account of the complex survey design

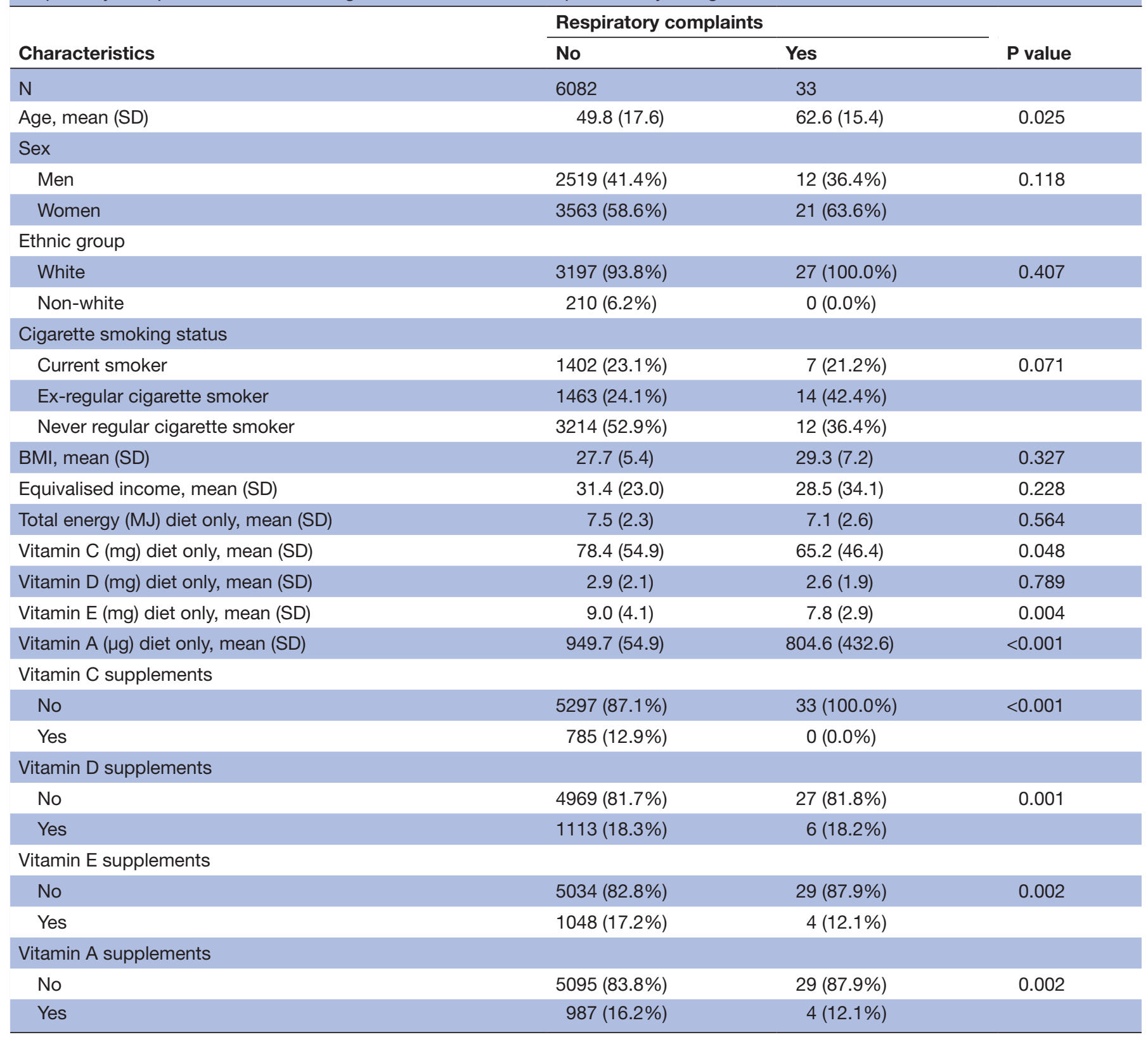

Values are displayed for the unweighed sample.

$P$ values take into account complex survey design.

$\mathrm{BMI}$, body mass index.

remaining non-statistically significant. No association between intake of vitamin $\mathrm{C}$ from diet and respiratory complaints was observed. The association with vitamin C supplements could not be estimated by the model as no adults with respiratory complaints reported taking vitamin $\mathrm{C}$ supplements.

Our current analysis suggests that intake of vitamin A and $\mathrm{E}$ from both diet and supplements is associated with a lower prevalence of respiratory complaints. Major dietary sources of vitamin A include liver, whole milk, cheese, in addition to carrots, dark green leafy vegetables and orange-coloured fruits. Vitamin A is also often added together with vitamin D to reduced fat spreads. Major dietary sources of vitamin $\mathrm{E}$ include vegetable oils, nuts and seeds. Vitamin E has been demonstrated to enhance $\mathrm{T}$ cell-mediated immune function, particularly among older adults. ${ }^{17}$ Accordingly, a randomised controlled trial of 617 older adults found that a daily supplements for 1 year with $200 \mathrm{IU}$ vitamin $\mathrm{E}$ led to a reduction in the risk of upper, but not lower, respiratory tract infections. ${ }^{18}$

Our findings of an association between vitamin $\mathrm{D}$ intake from supplements, but not diet, and lower respiratory 


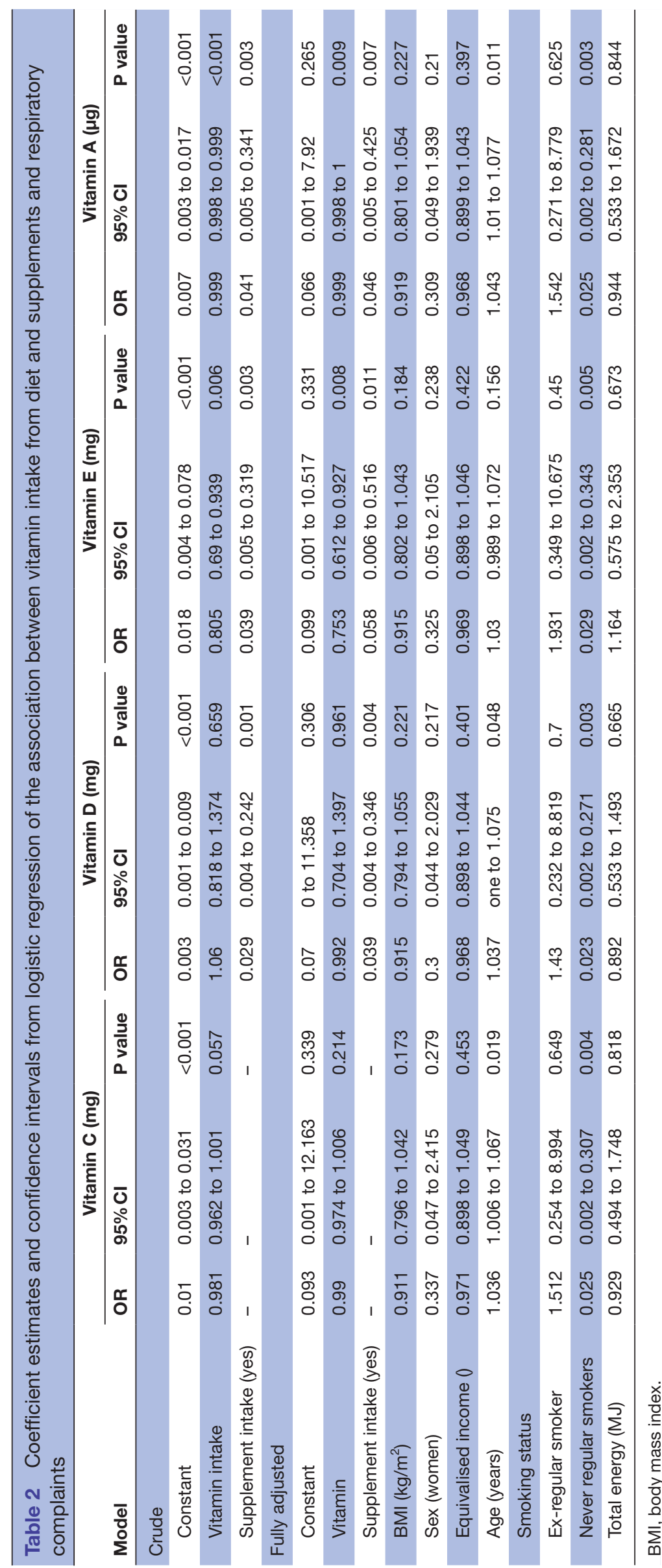


complaints add to the current scientific debate on this topic. Several studies have reported an inverse association between vitamin $\mathrm{D}$ intake and incidence of respiratory disorders. ${ }^{19}{ }^{20}$ In the UK BioBank Study, however, no relation between blood 25-hydroxyvitamin D concentration and COVID-19 infection were observed.$^{21}$ Our study indicates absence of a linear association between vitamin D intake from diet and respiratory complaints. Nonetheless, our study observed that vitamin D intake from supplements only is associated with reduced prevalence of respiratory complaints. It is estimated that around a fifth of the general population in the UK have low vitamin $\mathrm{D},{ }^{22}$ and over $30 \%$ of older adults aged 65 years and above do not achieve the recommended nutrient intake. ${ }^{23}$ This is despite recent increases in vitamin $\mathrm{D}$ intake in the general UK population. ${ }^{24}$ Our findings are consistent with the hypothesis that supplementation is critical to ensuring adequate vitamin $\mathrm{D}$ status is maintained and potentially indicate that intake of vitamin $\mathrm{D}$ from diet alone cannot help maintain adequate vitamin $\mathrm{D}$ status.

For vitamin $\mathrm{C}$, several meta-analyses have indicated that supplements with vitamin $\mathrm{C}$ prevent and treat pneumonia ${ }^{25}$ as well as the common cold. ${ }^{25}$ This association was not observed in our study. In addition to the above findings, no significant linear association was found between BMI and vitamin intake, or between BMI and respiratory complaints. This is in contrast to most recent studies indicating that obesity is associated with increased risk of $\mathrm{H} 1 \mathrm{~N} 1^{26}$ and COVID-19 viral infections, ${ }^{27}$ potentially via an augmented inflammatory cellular environment. ${ }^{27}$ Nonetheless, our study did not have data on the prevalence of the above infectious complaints, so no direct inferences could be made. Future studies are warranted to investigate the association between proinflammatory and pro-oxidant dietary patterns and prevalence or risk of respiratory complaints, particularly viral infections.

It is important to highlight that the current study investigated the association between total vitamin intake from diet and supplements and respiratory complaints as defined in the NDNS. Herein, the definition of respiratory complaints was broad and included both infectious and non-infectious diseases, such as colds, chronic obstructive pulmonary complaints and asthma. This implies that the generalisability of our study's findings is limited and no inferences should be made with regard to the current COVID-19 pandemic. Other limitations include the small number of cases and the inability to disentangle the direction of causality due to the cross-sectional nature of the NDNS study. Hence the associations highlighted are descriptive rather than causal.

\section{CONCLUSION}

In conclusion, in UK adults, intake of vitamin $\mathrm{A}$ and $\mathrm{E}$ from diet and supplements, and vitamin $\mathrm{D}$ from supplements is associated with lower self-reported prevalence of respiratory complaints. These findings provide some basis for further research into the value of vitamin intake up and beyond recommended dietary intake. Further research is required to assess the implications of the current study in the context of the current coronavirus disease 2019 pandemic using data from longitudinal cohorts. Our study also highlights the need for further data collection on nutrition and respiratory disorders to cover wider geographical areas and high-risk groups, including a focus on other ethnicities. This future research can form the basis for further recommendations for policy and practice.

Acknowledgements We would like to acknowledge the support of Professor Sumantra Ray for providing comments on behalf of COVID-19 task force from the NNEdPro Global Centre for Nutrition and Health.

Contributors SA conceptualised the study, conducted analysis and drafted the manuscript. LP reviewed the analysis, contributed to the writing and critical review of the manuscript.

Funding The authors have not declared a specific grant for this research from any funding agency in the public, commercial or not-for-profit sectors.

Competing interests SA and LP are members of the NNEdPro Global centre for Nutrition and Health.

Patient consent for publication Not required.

Provenance and peer review Not commissioned; externally peer reviewed.

Open access This is an open access article distributed in accordance with the Creative Commons Attribution Non Commercial (CC BY-NC 4.0) license, which permits others to distribute, remix, adapt, build upon this work non-commercially, and license their derivative works on different terms, provided the original work is properly cited, appropriate credit is given, any changes made indicated, and the use is non-commercial. See: http://creativecommons.org/licenses/by-nc/4.0/.

\section{REFERENCES}

1 Cascella M, Rajnik M, Cuomo A, et al. Features, evaluation and treatment coronavirus (COVID-19). StatPearls Publishing, 2020.

2 Ferguson N, Laydon D, Nedjati Gilani G. Report 9: impact of nonpharmaceutical interventions (NPIs) to reduce COVID19 mortality and healthcare demand, 2020.

3 Loeb M, High K. The effect of malnutrition on risk and outcome of community-acquired pneumonia. Respir Care Clin N Am 2005;11:99-108.

4 Vecchiarino P, Bohannon RW, Ferullo J, et al. Short-term outcomes and their predictors for patients hospitalized with communityacquired pneumonia. Heart Lung 2004;33:301-7.

5 Calder PC, Carr AC, Gombart AF, et al. Optimal nutritional status for a well-functioning immune system is an important factor to protect against viral infections. Nutrients 2020;12:1181.

6 Calder PC. Nutrition, immunity and COVID-19. BMJNPH 2020;3:74-92.

7 Butler MJ, Barrientos RM. The impact of nutrition on COVID-19 susceptibility and long-term consequences. Brain Behav Immun 2020;87:53-4.

8 Hemilä H, Louhiala P. Vitamin C for preventing and treating pneumonia. Cochrane Database Syst Rev 2013:CD005532.

9 Martineau AR, Jolliffe DA, Hooper RL, et al. Vitamin D supplementation to prevent acute respiratory tract infections: systematic review and meta-analysis of individual participant data. BMJ 2017;356:i6583.

10 The American Nutrition Association. Personalized nutrition \& the COVID-19 era, 2020. Available: https://theana.org/covid-19

11 Lanham-New SA, Webb AR, Cashman KD, et al. Vitamin D and SARS-CoV-2 virus/COVID-19 disease. BMJNPH 2020;3:106-10.

12 Caccialanza R, Laviano A, Lobascio F, et al. Early nutritional supplementation in non-critically ill patients hospitalized for the 2019 novel coronavirus disease (COVID-19): rationale and feasibility of a shared pragmatic protocol. Nutrition 2020;74:110835.

13 European Commission. EU register on nutrition and health claims. Available: https://ec.europa.eu/food/safety/labelling_nutrition/claims/ register/public/?event=search

14 Lennox A, Fitt E, ea WC. Appendix A to national diet and nutrition survey. results from years 1-4 (combined) of the rolling programme 
(2008/2009-2011/12). Dietary data collection and editing London: Public Health England, 2014.

15 England PH, Agency FS. National diet and nutrition survey results from years 5 and 6 (combined) of the rolling programme (2012/2013 -2013/2014), 2016. Available: https://assets.publishing.service. gov.uk/government/uploads/system/uploads/attachment_data/file/ 551352/NDNS Y5 6 UK Main Text.pdf

16 NatCen Social Research. National diet and nutrition survey (NDNS). Interviewer project instructions P1254. Available: http:// doc.ukdataservice.ac.uk/doc/6533/mrdoc/pdf/6533_ndns_yr7_ supporting_documents.pdf

17 Wu D, Meydani SN, Nikbin Meydani S. Age-associated changes in immune function: impact of vitamin $\mathrm{E}$ intervention and the underlying mechanisms. Endocr Metab Immune Disord Drug Targets 2014;14:283-9.

18 Meydani SN, Leka LS, Fine BC, et al. Vitamin E and respiratory tract infections in elderly nursing home residents: a randomized controlled trial. JAMA 2004;292:828-36.

19 Grant WB, Lahore H, McDonnell SL, et al. Evidence that vitamin D supplementation could reduce risk of influenza and COVID-19 infections and deaths. Nutrients 2020;12:988.

20 Ilie PC, Stefanescu S, Smith L. The role of vitamin D in the prevention of coronavirus disease 2019 infection and mortality. Aging Clin Exp Res 2020;32:1195-8.
21 Hastie CE, Mackay DF, Ho F, et al. Vitamin D concentrations and COVID-19 infection in UK Biobank. Diabetes Metab Syndr 2020;14:561-5.

22 Bates B, Cox L, Nicholson S, et al. National diet and nutrition survey results from years 5 and 6 (combined) of the rolling programme (2012/2013 - 2013/2014). Available: https://www.gov.uk/government/ statistics/ndns-results-from-years-5-and-6-combined2016.

23 Public Health England \& Food Standards Agency. Results from years 7 and 8 (combined) of the rolling programme (2014/2015 to 2015/2016), 2018. Available: https://dera.ioe.ac.uk/31298/ 1/NDNS_survey_results_from_years_7_and_8_of_the_rolling_ programme.pdf

24 Public Health England. NDNS: time trend and income analyses for years 1 to 9, 2019. Available: https://www.gov.uk/government/ statistics/ndns-time-trend-and-income-analyses-for-years-1-to-9

25 Hemilä $\mathrm{H}$, Chalker E. Vitamin $\mathrm{C}$ for preventing and treating the common cold. Cochrane Database Syst Rev 2013:CD000980.

26 Sun Y, Wang Q, Yang G, et al. Weight and prognosis for influenza A(H1N1)pdm09 infection during the pandemic period between 2009 and 2011: a systematic review of observational studies with metaanalysis. Infect Dis 2016;48:813-22.

27 Carter SJ, Baranauskas MN, Fly AD. Considerations for obesity, vitamin $\mathrm{D}$, and physical activity amid the COVID-19 pandemic. Obesity 2020;28:1176-7. 